\title{
A study of rivastigmine liposomes for delivery into the brain through intranasal route
}

\author{
KARTHIK ARUMUGAM \\ GANESA SUNDARARAJAN SUBRAMANIAN* \\ SURULIVEL RAJAN MALLAYASAMY \\ RANJITH KUMAR AVERINENI \\ MEKA SREENIVASA REDDY \\ NAYANABHIRAMA UDUPA \\ Department of Pharmaceutical \\ Quality Assurance, Manipal College \\ of Pharmaceutical Sciences \\ Manipal, Karnataka-576104 \\ India
}

Accepted June 24, 2008

\begin{abstract}
The present study is mainly aimed at delivering a drug into the brain via the intranasal route using a liposomal formulation. For this purpose, rivastigmine, which is used in the management of Alzheimer's disease, was selected as a model drug. Conventional liposomes were formulated by the lipid layer hydration method using cholesterol and soya lecithin as lipid components. The concentration of rivastigmine in brain and plasma after intranasal liposomes, free drug and per oral administration was studied in rat models. A significantly higher level of drug was found in the brain with intranasal liposomes of rivastigmine compared to the intranasal free drug and the oral route. Intranasal liposomes had a longer half-life in the brain than intranasally or orally administered free drug. Delivering rivastigmine liposomes through the intranasal route for the treatment of Alzheimer's disease might be a new approach to the management of this condition.
\end{abstract}

Keywords: rivastigmine, liposomes, intranasal administration, brain drug delivery, pharmacokinetics

Nasal drug delivery is an attractive approach for the systemic delivery of drugs with low oral bioavailability due to to extensive gastrointestinal breakdown or high hepatic first-pass effect. Intranasal delivery of drugs to reach the system has been widely studied and a number of reports is available in the literature (1). The concentration-time profiles of drugs achieved after nasal administration are often similar to those after intravenous administration, with resultant rapid onset of pharmacological activity (2). Intranasal delivery provides a convenient route for the delivery of drugs into brain. Around 35-40 substances have been reported to reach the central nervous system after nasal administration in experimental animals, e.g., carbamazepine (3), dopamine (4), neurotoxic metals (5), local anaesthetics (6), carboxylic acids (7) and the nerve growth factor (8). The olfactory region of the nasal passages has unique anatomic and physiologic attributes that provide both extracellular and intracellular pathways into the CNS bypassing the blood-brain barrier $(9,10)$. Alzheimer's disease (AD), a progressive neurodegenerative

\footnotetext{
* Correspondence, e-mail: ganrajesh@gmail.com
} 
brain disorder, is the most common cause of cognitive impairment (memory, intellect, personality) in the elderly. AD is characterized by the deposition of $\beta$ amyloid protein in the form of senile plaque deposits and formation of neurofibrillary tangles in the brain (11).

Rivastigmine is a novel acetyl cholinesterase (AChE) inhibitor used for the treatment of Alzheimer's disease. Both preclinical and clinical studies have shown that rivastigmine induces substantially greater inhibition of AChE in the central nervous system (CNS) compartment than in the periphery. Rivastigmine is rapidly and completely absorbed (> $96 \%$ of the administered dose). Peak plasma concentrations are reached in approximately 1 hour and absolute bioavailability after a 3-mg dose is about 36\%. Extensive, saturable first-pass metabolism leads to reduced bioavailability even though it is completely absorbed. Rivastigmine is rapidly and extensively metabolized, primarily via cholinesterase-mediated hydrolysis, to the decarbamylated metabolite (12).

Carrier systems play an important role in drug delivery into the system by overcoming limitations of the nasal route such as ciliary clearance, breakdown by nasal peptidase enzyme, etc. Liposomes are one of the carrier systems, that offers advantages such as better absorption and better drug retention in nasal mucosa $(13,14)$. Drugs like nifedipine and vaccines have been studied for incorporation into liposome formulations for systemic delivery $(15,16)$. Intranasal route of drug delivery is a promising route of drug delivery into the brain, which might be augmented using suitable carrier systems like liposomes, thereby enhancing CNS penetration of drugs and also delivering drugs in a sustained manner.

The aim of this study was to deliver rivastigmine into brain by administering it through the intranasal route using a novel carrier system such as liposome. The objectives included formulation of rivastigmine liposomes and its in vitro and in vivo evaluations, which included pharmacokinetics of rivastigmine in rat plasma and brain.

\section{EXPERIMENTAL}

Rivastigmine and venlafaxine were kindly donated by Torrent Pharmaceuticals, India. Soya lecithin (type II) and cholesterol were from Sigma Chemicals, USA. Dichloromethane, diethyl ether were from Ranbaxy Fine Chemicals, India. Methanol HPLC grade, acetonitrile HPLC grade, sodium dihydrogen phosphate and chloroform HPLC grade were from Merck, India. Orthophosphoric acid was from SD Fine Chemicals Ltd., India. All other reagents and chemicals used were of analytical grade.

\section{Preparation of rivastigmine liposomes}

In the present study, multi lamellar liposomes were prepared by the lipid layer hydration method (20). Soya lecithin and cholesterol were weighed (4:1 molar ratio) and dissolved in chloroform and transferred to a 100-mL round bottom flask. The flask was attached to a rotary evaporator (Serwell Instruments, India) immersed in a $45.0^{\circ} \mathrm{C}$ water bath and rotated under vacuum. This process continued until all the liquid evaporated and a dry thin lipid film was deposited on the walls of the flask. The flask was left in a 
vacuum desiccator overnight to ensure complete removal of residual solvent. Then, the drug was dissolved in phosphate buffer saline (PBS) pH 7.4 added to the dried film and vortexed for 10 minutes. Liposome suspension was then subjected to three freezing-thawing cycles, freezing at $-80^{\circ} \mathrm{C}$ and then thawing in a water bath at $30{ }^{\circ} \mathrm{C}$. The liposomal suspension was stored at $4{ }^{\circ} \mathrm{C}$ until analysis.

\section{Evaluation of liposomes}

Encapsulation efficiency. - Drug encapsulation efficiency was determined by the minicolumn centrifugation method (17). Disposable syringes $(1 \mathrm{~mL})$ were first plugged with cotton and packed with hydrated Sephadex G-25M gel $(1 \%, m / V)$. Sephadex G-25 was previously soaked in $0.9 \%(V / V)$ saline for $4 \mathrm{~h}$. These syringes were placed in plastic centrifugal tubes and the whole assembly was centrifuged at $6700 \times g$ for $15 \mathrm{~min}$ to make the bed dry. To this dried bed, $500 \mu \mathrm{L}$ of liposomal suspension was added and the assembly was centrifuged at $600 \times g$ for $15 \mathrm{~min}$. The encapsulated drug was separated based on the molecular size. This process was repeated three times using fresh syringes packed with gel each time to ensure complete removal of non-entrapped free drug. The concentration of the encapsulated drug was estimated by the HPLC method.

The HPLC system consisted of a Shimadzu LC-10 ADVP system with LC1OAT-VP pump and SPD M-10AVP photo diode array detector. Mobile phase consisted of 20 mmol L-1 phosphate buffer $\mathrm{pH} 3.0$ and acetonitrile $(75: 25 \%, V / V)$ at a flow rate of $1 \mathrm{~mL}$ $\min ^{-1}$. The stationary phase was Kromasil $C_{8}(250 \times 4.6 \mathrm{~mm}, 5 \mu \mathrm{m})$. The detection wavelength was kept at $210 \mathrm{~nm}$.

\section{Morphological studies}

Optical microscopy. - Formation of multilamellar vesicles was confirmed by examining the liposomal suspension under an optical microscope with the magnification power of 40 x (Olympus CX41, Philippines).

Scanning electron microscopy. - The surface morphology of liposomes was studied using scanning electron microscopy (Hitachi model S-3000H, Japan). The resolution of $3.5 \mathrm{~nm}$ was used with a secondary electron image display. The liposomes were coated with gold-palladium alloy (150-250 ̊) using a sputter coater. The coater was operated at $2.2 \mathrm{kV}, 20 \mathrm{mV}, 13.33 \mathrm{~Pa}$ (argon) for 90 seconds. Accelerating voltage of $15 \mathrm{kV}$ and magnification of $200 \times$ were used to scan the liposomes.

\section{Particle size measurement}

The particle size of liposomes was measured using a particle size analyzer (Malvern Mastersizer 2000, UK). The liposome size distribution profile was determined by light scattering based on the laser diffraction method. Liposomes were immersed in oil medium before measurement. All measurements were carried out at $25 \pm 1^{\circ} \mathrm{C}$ by scattering light at $90{ }^{\circ} \mathrm{C}$. 


\section{In vitro release studies}

The in vitro release of rivastigmine from the liposomal formulation was determined by the dialysis sac method (Sigma membrane, $M_{\mathrm{r}}$ cut off 10,000 ). Simulated nasal fluid (SNF) was used as medium for in vitro release studies. The $\mathrm{pH}$ of solution was maintained within the $\mathrm{pH}$ range of 6.2-6.8. About $1 \mathrm{~mL}$ of liposomal suspension was placed in the dialysis sac, which was immersed in $100 \mathrm{~mL}$ of SNF maintained at $37{ }^{\circ} \mathrm{C}$ and stirred with a magnetic stirrer. Samples of $1 \mathrm{~mL}$ were drawn at predetermined time intervals of $5,15,25,35,45,60,90,120,150,180,240,300$ and 360 minutes. In order to maintain sink conditions, an equal volume of SNF was replaced. The samples were analyzed by the HPLC method (as mentioned under encapsulation efficiency) to determine the concentration. This experiment was done in triplicate and the average percentage release was calculated.

\section{Stability studies}

The stability of rivastigmine liposomes was assessed by subjecting liposomal suspensions to different temperature conditions, i.e., $4{ }^{\circ} \mathrm{C}$ (refrigerator) and accelerated conditions $25 \pm 2{ }^{\circ} \mathrm{C}, 60 \pm 5 \%$ relative humidity (RH) (thermo stability chamber) for a period of 3 months. Liposomal suspensions were kept in sealed ampoules (2-mL capacity) after flushing with nitrogen. Samples were withdrawn periodically and analyzed by HPLC to determine the drug content.

\section{Bioanalytical HPLC method}

Chromatographic separation was achieved with a reverse phase Grace Vydac monomeric column $\mathrm{C}_{18}(4.6 \times 250 \mathrm{~mm}) 5 \mu \mathrm{m}$ and the mobile phase consisted of $20 \mathrm{mmol} \mathrm{L}^{-1}$ phosphate buffer $\mathrm{pH} 3.0$ and acetonitrile $(75: 25)$ with flow rate of $1 \mathrm{~mL} \mathrm{~min}^{-1}$. The effluents were measured by fluorimetric detection with excitation and emission wavelength at 220 and $293 \mathrm{~nm}$, respectively.

Extraction of rivastigmine from the plasma and brain sample was carried out using the liquid-liquid extraction (LLE) technique. $100 \mu \mathrm{L}$ of rat plasma or brain sample was mixed with $20 \mu \mathrm{L}$ of the internal standard (venlafaxine) working stock solution (50 $\mu \mathrm{g}$ $\mathrm{mL}^{-1}$ ) and was vortexed for $60 \mathrm{~s}$. Then $2 \mathrm{~mL}$ of dichloromethane was added and centrifuged at $1677 \times g$ for $5 \mathrm{~min}$. Clear $1.8 \mathrm{~mL}$ of organic layer was separated and evaporated in a turbo vap LV Evaporator (Zymark, USA) at $40{ }^{\circ} \mathrm{C}$ under a nitrogen stream. The dried residue was then reconstituted with $200 \mu \mathrm{L}$ of mobile phase and $40 \mu \mathrm{L}$ was subjected for HPLC analysis. The analysis was carried out on a Shimadzu LC-10 series chromatographic system (Shimadzu) equipped with a LC10AT-VP pump and RF-10AXL fluorescence detector.

\section{In vivo studies}

Plasma pharmacokinetics study. - Animal studies were carried out using male Wistar rats after obtaining the Institutional Animal Ethics Committee Approval. The animals were maintained under controlled conditions with temperature of $25{ }^{\circ} \mathrm{C}$ and $\mathrm{RH}$ of $45 \%$ in polypropylene cages filled with sterile paddy husk. They were fed a balanced diet 
and water ad libitum. The rats were divided into three groups, each containing six rats weighing about 200-250 g. Animals were fasted overnight before the study. Group I was administered oral rivastigmine and group II received rivastigmine free drug intranasally. Animals were kept in the supine position for 2 minutes after administration of the nasal dose. Group III was administered intranasal rivastigmine liposomes. All three groups reccived $1.08 \mathrm{mg} \mathrm{kg}^{-1}$ b.m. rivastigmine. About $300-\mu \mathrm{L}$ blood samples were collected into the EDTA-added centrifuge tubes at predetermined time intervals of 5, 10, 15, $30,45,60,120,180,300,480$ and 720 minutes from the retro orbital vein by using heparinized capillary tubes. Blood samples were centrifuged at $1700 \times g$ (Remi cooling centrifuge, India) for 5 minutes at $0{ }^{\circ} \mathrm{C}$. The plasma was separated and stored at $-20{ }^{\circ} \mathrm{C}$. The rivastigmine concentration in plasma was determined by HPLC.

\section{Brain pharmacokinetics study}

The rats were divided into three groups. Group I had 27 animals and other groups had 18 animals each. Group I was administered rivastigmine throught the oral route. Group II received rivastigmine intranasally, and the third group was administered the rivastigmine liposomes through the intranasal route. All three groups were administraced $1.08 \mathrm{mg} \mathrm{kg}^{-1} \mathrm{~b} . \mathrm{m}$. rivastigmine. Three animals per time interval were dissected at 15 , 30, 45, 60, 120 and 180 minutes for all three groups. For group III, three additional time points (240, 360 and 720 minutes) were included. After administration of the dose, the animals were sacrificed by the cervical necrosis method and then the brain was removed and washed twice with saline, which was then wiped with a soft tissue and weighed and stored in freezer until analysis. The brain tissue was homogenized with phosphate buffer saline ( $\mathrm{pH}$ 7.4) under cool conditions and samples were extracted and analyzed by HPLC.

\section{Pharmacokinetic parameters}

Pharmacokinetic parameters were evaluated using PK solution 2.0 software (non-compartmental modeling) and statistical evaluation was carried out using the Graph Pad Prism software package (Version 4.03). Pharmacokinetic parameters such as $c_{\max }$, $t_{\text {max }}, k_{\mathrm{el},}, A U C_{0}$ to $\alpha$, and $t_{1 / 2}$ were calculated for all groups.

\section{RESULTS AND DISCUSSION}

Encapsulation efficiency of the developed formulation was found to be $80.0 \pm 5.0 \%$. The morphological study with optical microscopy and scanning electron microscopy (Fig. 1) showed that the developed liposomes had a smooth surface and were spherical in shape with multilamellar vesicles. The particle size of liposomes $(>90 \%)$ was found to be $10.0 \pm 2.8 \mu \mathrm{m}$ (Table I).

Cumulative drug release was found to be $56.0 \pm 2.3 \%$ after 6 hours (Fig. 2). Release studies showed that there was a burst release initially and then release followed a log phase. The plateau observed after one hour might be due to equilibration of drug concentration between the donor and receptor compartments. 
Fig. 1. Scanning electron microscopy of rivastigmine liposomes.

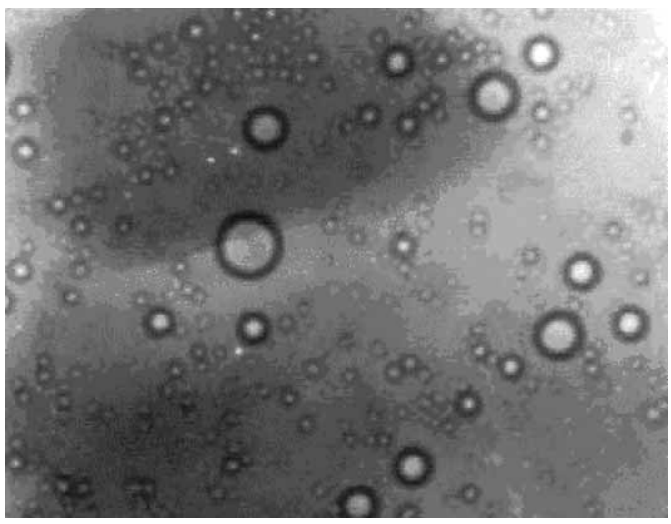

Table I. Characterization of rivastigmine liposomes

\begin{tabular}{lc}
\hline \multicolumn{1}{c}{ Parameter } & Means \pm SD $^{\mathrm{a}}$ \\
\hline Particle size $(\mu \mathrm{m})$ & $10.0 \pm 2.8$ \\
Encapsulation efficiency $(\%)$ & $80.0 \pm 5.0$ \\
Surface morphology & Smooth \\
Shape & Spherical \\
Drug release after $6 \mathrm{~h}(\%)$ & $56.0 \pm 2.3$ \\
Stability after 3 months at $4{ }^{\circ} \mathrm{C}(\%)$ & $95.1 \pm 3.6$ \\
Stability after 3 months at $25^{\circ} \mathrm{C} / 60 \% \mathrm{RH}(\%)$ & $85.8 \pm 2.4$ \\
\hline
\end{tabular}

$$
\text { a } n=3
$$

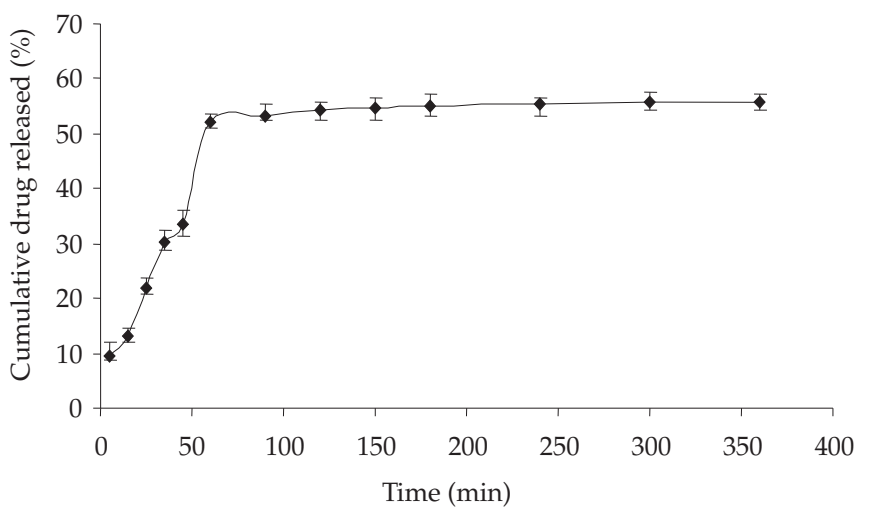

Fig. 2. In vitro release of rivastigmine from liposomes (mean $\pm \mathrm{SD}, n=3$ ). 
All stability studies were carried out in glass bottles (type II USP glass containers) (18) made of treated soda lime glass. Stability studies were carried out at $4{ }^{\circ} \mathrm{C}$ and 25 ${ }^{\circ} \mathrm{C} / 60 \% \mathrm{RH}$ for a period of 3 months and the percentage drug content is shown Table I. The physical stability of liposomes showed that none of the samples were agglomerated. The percentage drug content at the end of three months was found to be $95.2 \pm 3.6$ and $85.8 \pm 2.4$ at $4^{\circ} \mathrm{C}$ and $25^{\circ} \mathrm{C}$, respectively. The results indicated that the developed liposome formulation should be stored at $4{ }^{\circ} \mathrm{C}$.

\section{HPLC validation}

The developed in-house method was very sensitive to quantify rivastigmine in plasma and brain in very low concentrations $\left(10 \mathrm{ng} \mathrm{mL}^{-1}\right)$. The method was selective for the analyte and there was no interference from endogenous compounds at the retention time of rivastigmine and internal standard. The typical chromatogram of rivastigmine and internal standard is shown in Fig. 3. The calibration line concentration range was between 10-3000 $\mathrm{ng} \mathrm{mL} \mathrm{m}^{-1}\left(R^{2}=0.9998\right)$. The mean extraction recovery of rivastigmine from plasma and brain tissue homogenate was $80.8 \pm 1.1 \%$ and $85.0 \pm 1.2 \%$, respectively. The intra- and inter-day precision $(n=6)$ ranged from 2.3 to $5.7 \%$. The intra- and inter-day accuracy $(n=6)$ showed that the developed method was accurate and the $\%$ bias was 7.0 and $6.0 \%$, respectively.

\section{In vivo studies}

Rivastigmine concentration in plasma after oral and nasal administration as free drug and after intranasal administration of liposomal preparation is given in Table II. When $A U C s$ of these groups were compared, the intranasal liposome group had five-fold higher AUC $\left(36.13 \pm 1.87 \mu \mathrm{g}\right.$ min $\left.\mathrm{mL}^{-1}\right)$ when compared to orally administered free drug $\left(6.58 \pm 0.26 \mu \mathrm{g} \mathrm{min} \mathrm{mL}^{-1}\right)$ and an almost three-fold higher value compared free drug administrated intransally $\left(12.99 \pm 0.87 \mu \mathrm{g} \min \mathrm{mL}^{-1}\right)$.

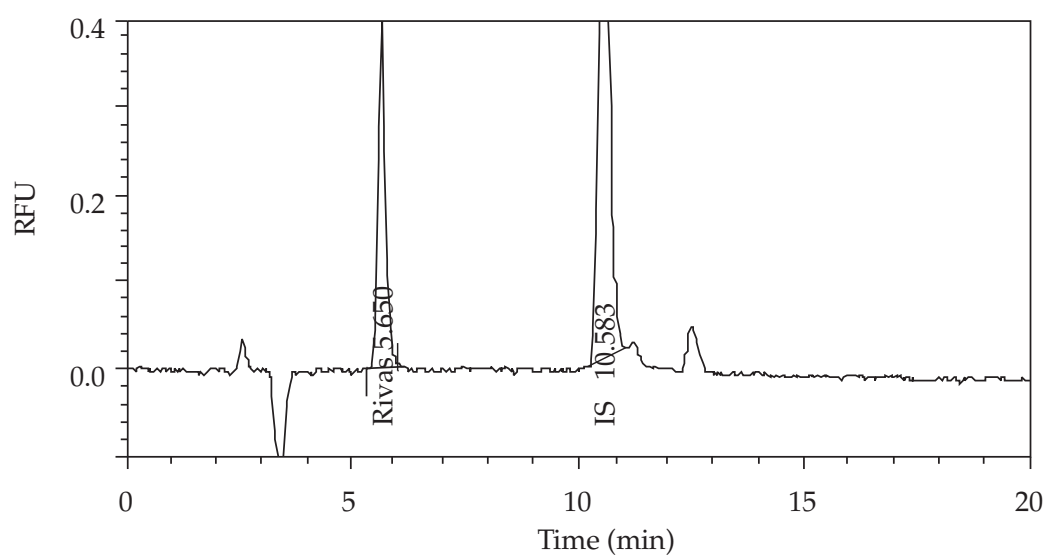

Fig. 3. Typical chromatogram of rivastigmine and internal standard. 
K. Arumugam et al.: A study of rivastigmine liposomes for delivery into the brain through intranasal route, Acta Pharm. 58 (2008) 287-297.

Table II. Plasma pharmacokinetic parameters of rivastigmine following various routes of administration ${ }^{a}$

\begin{tabular}{cccc}
\hline Parameter & Free drug (oral) & Free drug (intranasal) & Liposomes intranasal \\
\hline$A U C_{(0-\infty)}$ & $6.58 \pm 0.26^{\mathrm{b}}$ & $12.99 \pm 0.87^{\mathrm{d}}$ & $36.13 \pm 1.87^{\mathrm{b}, \mathrm{d}}$ \\
$\left(\mu \mathrm{g} \min \mathrm{mL}^{-1}\right)$ & $0.06 \pm 0.02^{\mathrm{b}}$ & $0.35 \pm 0.05^{\mathrm{d}}$ & $0.60 \pm 0.04^{\mathrm{b}, \mathrm{d}}$ \\
$c_{\max }\left(\mu \mathrm{g} \mathrm{mL}^{-1}\right)$ & $15 \pm 4^{\mathrm{b}}$ & $5 \pm 3^{\mathrm{d}}$ & $30 \pm 9^{\mathrm{b}, \mathrm{d}}$ \\
$t_{\max }(\min )$ & $128.57 \pm 21.69^{\mathrm{c}}$ & $63.78 \pm 16.23^{\mathrm{d}}$ & $109.28 \pm 16.92^{\mathrm{b}, \mathrm{d}}$ \\
$t_{1 / 2}(\min )$ & &
\end{tabular}

a Mean $\pm \mathrm{SD}, n=6$.

b Significant difference between free drug oral $v s$. intranasal liposomes, $p<0.01(99 \% C I)$.

c Significant difference between free drug oral vs. intranasal liposomes, $p<0.05(95 \% C I)$.

d Significant difference between free drug intranasal vs. intranasal liposomes, $p<0.01$ (99\% CI).

When $c_{\max }$ and $t_{\max }$ were compared, nasally administered free drug reached its peak within 5 minutes $\left(c_{\max }=0.35 \mu \mathrm{g} \mathrm{mL}{ }^{-1}\right)$ whereas the intranasal liposomal formulation attained its peak in 45 minutes with a $c_{\max }$ of $0.60 \mu \mathrm{g} \mathrm{mL}^{-1}$ (Fig. 4a).

Intranasal liposome group was compared with the oral free drug group and it was found that liposomal formulation had 10 times higher $c_{\max }$. Higher systemic AUC was observed with intranasal rivastigmine liposomes compared to free drug. Intranasal free drug attained earlier peak than liposomal drug. This phenomenon could be explained by the fact that free drug reached the systemic circulation rapidly via the nasal route whereas liposomal drug might have been accumulated into the nasal mucosa and released slowly into the circulation delaying its $t_{\max }$ but almost doubling its $c_{\max }$ compa-
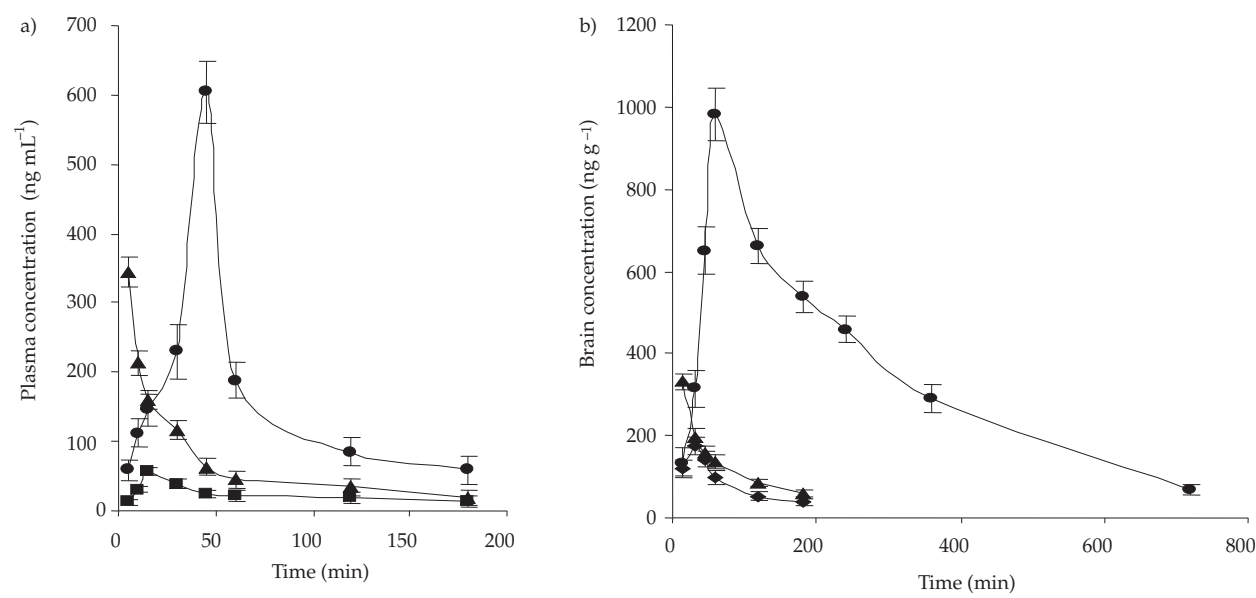

Fig. 4. Rivastigmine time profiles after various routes of administration in: a) plasma (mean $\pm S D$, $n=6$ ); b) brain (mean $\pm \mathrm{SD}, n=3$ ); free drug oral ( - ), free drug intranasal ( $\longrightarrow$ ), liposomes intranasal (- -$)$. 
K. Arumugam et al.: A study of rivastigmine liposomes for delivery into the brain through intranasal route, Acta Pharm. 58 (2008) $287-297$

Table III. Pharmacokinetic parameters of rivastigmine in brain following various routes of administration ${ }^{a}$

\begin{tabular}{cccc}
\hline Parameter & Free drug (oral) & Free drug (intranasal) & Liposomes (intranasal) \\
\hline$A U C_{(0-\infty)}\left(\mu \mathrm{g} \mathrm{min} \mathrm{mL} \mathrm{mL}^{-1}\right)$ & $20.72 \pm 1.25^{\mathrm{b}}$ & $126.37 \pm 11.76^{\mathrm{d}}$ & $408.18 \pm 22.47^{\mathrm{b}, \mathrm{d}}$ \\
$\left.c_{\max }(\mu \mathrm{g} \mathrm{mL})^{-1}\right)$ & $0.17 \pm 0.18^{\mathrm{b}}$ & $0.33 \pm 0.29^{\mathrm{d}}$ & $0.98 \pm 0.74^{\mathrm{b}, \mathrm{d}}$ \\
$t_{\max }(\min )$ & $30 \pm 6^{\mathrm{c}}$ & $15 \pm 4^{\mathrm{d}}$ & $60 \pm 19^{\mathrm{c}, \mathrm{d}}$ \\
$t_{1 / 2}(\mathrm{~min})$ & $118 \pm 15^{\mathrm{b}}$ & $115 \pm 16^{\mathrm{d}}$ & $173 \pm 14^{\mathrm{b}, \mathrm{d}}$ \\
\hline
\end{tabular}

a Mean $\pm \mathrm{SD}, n=3$.

b Significant difference between free drug oral vs. intranasal liposomes, $p<0.01(99 \% C I)$.

c Significant difference between free drug oral $v$ s. intranasal liposomes, $p<0.05(95 \% C I)$.

d Significant difference between free drug intranasal $v s$. intranasal liposomes, $p<0.01$ (99\% CI).

red to free drug. A similar result was reported by Barakat et al. (3), who studied absorption of carbamazepine after intranasal administration.

When rivastigmine concentrations in the brain were studied after oral and intranasal administrations, intranasal administration attained 5.6 times higher concentration in the brain than oral administration. Intranasal free drug attained $t_{\max }$ within 15 min whereas intranasal liposomes reached $t_{\max }$ in $60 \mathrm{~min}$. Liposomal formulation had a longer half-life (173 $\mathrm{min}$ ) than oral administration (118 min) (Table III, Fig. 4b).

Lipophilicity, molecular mass, route of administration and P-glycoprotein efflux are the factors considered to determine the transfer of drugs across blood brain barrier (19). This study is also in conformity with the factors stated above, since the liposomal formulation achieved better absorption into the brain following intranasal administration compared to the free drug. This might also be due to direct transfer of the drug from nasal mucosa to the brain via the olfactory route. A number of authors have worked in this area of the nasal-brain pathway and have consistently shown that intranasal delivery is a promising route for delivery of drugs into the CNS system (20).

\section{CONCLUSIONS}

Intranasal administration of rivastigmine liposomes significantly increased the exposure and resulted in its higher concentration in the brain. Sustained release of rivastigmine from the liposomes may be used to reduce the frequency of administration and increase patient compliance. Demonstration of direct delivery of rivastigmine into the brain in significant quantities might help further research in this area and studies of its implications for the clinical practice.

Acknowledgements. - The authors are grateful to Mr. Murali of AIIMS, New Delhi, and Mr. Manivel of Strides Arcolab, Bangalore, for their help with characterization of liposomes. 


\section{REFERENCES}

1. Y. W. Chien and Y. Chang, Historical Developments of Transnasal Systemic Medications, in Transnasal Systemic Medications: Fundamentals, Developmental Concepts and Biomedical Assessments (Ed. Y. W. Chien), Elsevier, Amsterdam 1985, pp. 1-100.

2. A. A. Hussain, Intranasal drug delivery, Adv. Drug Deliv. Rev. 29 (1998) 39-4; DOI: 10.1016/ S0169-409X (97)00060-4.

3. N. S. Barakat, S. A. Omar and A. A. E. Ahmed, Carbamazepine uptake into rat brain following intra-olfactory transport, J. Pharm. Pharmacol. 58 (2005) 63-72; DOI: 10.1211/jpp.58.1.0008.

4. M. Dahlin, U. Bergman, B. Jansson, E. Bjork and E. Brittebo, Transfer of dopamine in the olfactory pathway following nasal administration in mice, Pharm. Res. 17 (2000) 737-742; DOI: 10.1023/ A:1007542618378.

5. J. Henriksson and H. Tjalve, Uptake of inorganic mercury in the olfactory bulbs via olfactory pathways in rats, Environ. Res. 77 (1998) 130-140; DOI:10.1006/enrs.1997.3817.

6. K. J. Chou and M. D. Donovan, Lidocaine distribution into the CNS following nasal and arterial delivery: a comparision of local sampling and microdialysis techniques, Int. J. Pharm. 171 (1998) 53-61; DOI: 10.1016/S0378-5173(98)00170-7s.

7. C. Eriksson, U. Bergman, A. Franzen, M. Sjoblom and E. B. Brittebo, Transfer of some carboxylic acids in the olfactory system following intranasal administration, J. Drug Target. 7 (1997) 131-142.

8. W. H. Prey, J. Liu, X. Chen, R. G. Thorne, J. R. Fawcett, T. A. Ala and Y. E. Rahman, Delivery of 125I-NGF to the brain via the olfactory route, Drug Deliv. 4 (1997) 87-92; DOI: 10.3109/ 10717549709051878.

9. R. G. Thorne, C. R. Emory, T. A. Ala and W. H. Frey, Quantitative analysis of the olfactory pathway for drug delivery to the brain, Brain Res. 692 (1995) 278-282; DOI: 10.1016/0006-8993(95) 00637-6.

10. L. Illum, Transport of drugs from the nasal cavity to the central nervous system, Eur. J. Pharm. Sci. 11 (2000)1-18; DOI: 10.1016/S0928-0987(00)00087-7.

11. J. L. Cummings and G. Cole, Alzheimer disease, JAMA 287 (2002) 2335-2338; DOI: 10.1001/jama.287.18.2335.

12. R. J. Polinsky, Clinical pharmacology of rivastigmine: A new generation acetyl choline esterase inhibitor for the treatment of Alzheimer's disease, Clin. Ther. 20 (1998) 634-637; DOI: 10.1016/ S0149-2918(98)80127-6.

13. K. Muramatsu, Y. Maitani, K. Takayama and T. Nagai, The relationship between the rigidity of the liposomal membrane and the absorption of insulin after nasal administration of liposomes modified with an enhancer containing insulin in rabbits, Drug Dev. Ind. Pharm. 25 (1999) 1099-1105; DOI: $10.1081 /$ DDC-100102275.

14. S. L. Law, K. J. Huang and H. Y. Chou, Preparation of desmopressin-containing liposomes for intranasal delivery, J. Control. Rel. 70 (2001) 375-382; DOI: 10.1016/S0168-3659(00)00369-2.

15. K. Iwanaga, S. Matsumoto, K. Morimoto, M. Kakemi, S. Yamashita and T. Kimura, Usefulness of liposomes as an intranasal dosage formulation for topical drug application, Biol. Pharm. Bull. 23 (2000) 323-326.

16. K. A. Edwards, and A. J. Baeumner, Analysis of liposomes, Talanta 68 (2006) 1432-1441; DOI: 10.1016/j.talanta.2005.08.031.

17. E. Maria, B. Estradaa, M. Foldvari, M. Snider and K. Harding, Intranasal immunization with liposome-formulated Yersinia pestis vaccine enhances mucosal immune responses, Vaccine 18 (2000) 2203-2211; DOI: 10.1016/S0264-410X(00)00019-0.

18. United States Pharmacopoeia 23, National Formulary 18, USP Convention, Rockville, 2005. 
K. Arumugam et al.: A study of rivastigmine liposomes for delivery into the brain through intranasal route, Acta Pharm. 58 (2008) 287-297.

19. B. J. Balin, R. D. Broadwell, M. Salcman and M. El-Kalliny, Avenues for entry of peripherally administered protein to the central nervous system in mouse, rat, and squirrel monkey, J. Comp. Neurol. 251 (1986) 260-280; DOI: 10.1002/cne.902510209.

20. M. P. van den Berg, J. Coos Verhoef, S. G. Romeijn and F. W. H. M. Merkus, Uptake of estradiol or progesterone into the CSF following intranasal and intravenous delivery in rats, Eur. J. Pharm. Sci. 58 (2004) 131-135; DOI: 10.1016/j.ejpb.2004.02.010.

$S A \check{Z} E T A K$

\section{Liposomi rivastigmina za isporuku $\mathbf{u}$ mozak intranazalnim putem}

KARTHIK ARUMUGAM, GANESA SUNDARARAJAN SUBRAMANIAN, SURULIVEL RAJAN MALLAYASAMY, RANJITH KUMAR AVERINENI, MEKA SREENIVASA REDDY AND i NAYANABHIRAMA UDUPA

Glavni cilj rada je razvoj liposoma za intranazalnu primjenu za isporuku lijeka u mozak. U tu svrhu izabran je rivastigmin kao modelni lijek koji se upotrebljava u terapiji Alzheimerove bolesti. Liposomi su pripravljeni metodom hidratacije lipidnog sloja koristeći kolesterol i lecitin iz soje kao lipidne komponente. Praćena je koncentracija rivastigmina u mozgu i plazmi nakon intranazalne i peroralne primjene liposoma i slobodnog lijeka. S intranazalnim liposomima rivastigmina postignuta je značajno veća koncentracija lijeka u mozgu. Osim toga intranazalni liposomi imaju dulje vrijeme poluživota u mozgu. Intranazalna primjena liposoma rivastigmina mogla bi predstavljati novi pristup terapiji Alzheimerove bolesti.

Ključne riječi: rivastigmin, liposomi, intranazalna primjena, isporuka lijeka u mozak, farmakokinetika

Department of Pharmaceutical Quality Assurance, Manipal College of Pharmaceutical Sciences, Manipal, Karnataka-576 104, India 